\title{
La noción de armonía de Plotino a Jámblico
}

\author{
The notion of harmony from Plotinus to lamblichus
}

\begin{abstract}
José María Zamora Calvo
Profesor titular de Filosofía Antigua en el Departamento de Filosofía de la Universidad Autónoma de Madrid, Doctor en Filosofía con premio extraordinario por la Universidad de Valladolid - España, e-mail: jm.zamora@uam.es
\end{abstract}

\section{Resumen}

En la Sentencia 18 Porfirio se inspira en un pasaje plotiniano de En. III 6 [26] 4, 41-52, donde trata precisamente sobre la sensación, pero introduciendo dos innovaciones relevantes: 1) la noción de ser vivo, donde Plotino menciona solo la parte pasiva del alma y la materia - lo que constituye una manera de insistir en la relación íntima que se da entre el alma y el cuerpo en el compuesto-; y 2) las nociones de "armonía no separada" y de "armonía separada", donde Plotino alude solo a una armonía que hace vibrar ella misma las cuerdas y que dicta su regla al músico. La armonía separada puede intensificarse con la relación armónica que existe en sí, independiente del instrumento y de la interpretación musical. Asimismo, para trazar un paralelismo entre la armonía de la lira y el estado de inherencia del alma, Jámblico se refiere a la concepción plotiniano-porfiriana del ser vivo: el animal es el cuerpo que posee una naturaleza particular y que ha sido vivificada

1 Este trabajo se ha llevado a cabo en el marco del proyecto de investigación "Éticas griegas y filosofía contemporánea", subvencionado por el Ministerio español de Economía y Competitividad (Ref. FFI2009-09498). 
no por el alma, sino por una especie de derivado del alma que denomina "huella" o "luz" del alma, por lo que el alma misma no se une al cuerpo.

Palabras-clave: Armonía. Neoplatonismo. Plotino. Porfirio. Jámblico.

\section{Abstract}

In Sentence 18 Porphyry is inspired by a Plotinian passage of Enn. III 6 [26] 4, 41-52, which is precisely about the feeling, but he introduced two relevant innovations: 1) the notion of living being, where Plotinus mentions only the passive part of the soul and matter - what constitutes a way of insisting on the intimate relationship that exists between soul and body in the compound, and; 2) the notions of "not separate harmony" and "separate harmony", in which Plotinus referred only to a harmony that vibrates the string itself and dictates its rule to the musician. Separate harmony can be intensified by the harmonic relationship that exists in itself, independently of the instrument and the musical interpretation. Also, in order to draw a parallel between the harmony of the lyre and the state of inherence of the soul, lamblichus refers to the Plotinian-Porphyrian conception of living being: the animal is the body that has a particular nature and which has been enlivened not by the soul, but by a kind of derivative of soul called "footprint" or "light" of the soul, so that the soul itself does not join to the body.

Keywords: Harmony. Neoplatonism. Plotinus. Porphyry. Iamblichus.

Entre la Sentencia 18 de Porfirio y el pasaje plotiniano de En. III 6 [26] 4, 41-52 $2^{2}$ puede trazarse un claro paralelismo. En ambos textos:

1) La armonía en tanto forma representa el alma - para Plotino "como una armonía que pulsara las cuerdas por sí misma" y para Porfirio "se parece a una armonía separada".

2 El procedimiento que hemos adoptado a la hora de citar el texto de las Enéadas de Plotino sigue el método generalmente más utilizado por los investigadores. El número romano indica el número de la Enéada, y el arábigo, el número del tratado - según la ordenación sistemática de Porfirio -, la cifra entre corchetes señala el número del tratado según el orden cronológico, la siguiente cifra indica el número del capítulo, y los números de línea se hallan al final separados por un guión. Así, por ejemplo, En. V, 1 [10] 2, 1-4: se refiere al pasaje de la Enéada V, tratado primero, décimo cronológicamente, capítulo segundo, líneas 1 al 4. Estas referencias se corresponden a la editio minor de Henry-Schwyzer (1964-1982).

Las abreviaturas utilizadas son las siguientes: En: PLOTINO, E.; Sent.: PORFIRIO, S.; SVF: Stoicorum Veterum Fragmenta

Rev. Filos., Aurora, Curitiba, v. 24, n. 34, p. 357-373, jan./jun. 2012 
2) El músico, habitado por la armonía, representa el viviente, habitado por el alma - uno y otro son causa del movimiento de las cuerdas; y la armonía, en tanto forma, es causa de ese movimiento.

3) por último, las cuerdas, puestas en movimiento, representan los cuerpos, cuyas partes afectivas son pulsadas por la afección. Ahora bien, Jámblico marca distancia respecto a sus antecesores, y en uno de los extractos que conservamos de su tratado Sobre el alma, introduce la doctrina de los números del alma, que son los que confieren armonía al mundo físico "de acuerdo con los principios racionales preexistentes en su esencia".

\section{Plotino: la armonía que pulsa las cuerdas por sí misma}

El alma sigue siendo incorpórea aunque esté unida a un cuerpo, ya que el cuerpo no representa un obstáculo para que conserve las características de los incorporales (cf. Porph. Sent. 27, li. 1-5). De ahí que el alma unida a un cuerpo sigue siendo una forma, $\mathrm{y}$, en tanto forma, permanece impasible. Cuando se producen las sensaciones, solo el cuerpo padece. La forma puede provocar el movimiento de la pasión porque está presente en la materia y actúa por esa presencia. Plotino acude al ejemplo de la armonía para explicar de qué modo esa presencia puede manifestarse.

Pero no; esa parte afectiva del alma no es un cuerpo, sino una forma. En la materia, sin embargo, tienen su sede tanto la facultad apetitiva como, en particular, la nutritivo-incrementativo-generativa, la cual es raíz y principio de la forma apetitivo-afectiva. Ahora bien, ninguna forma debe admitir en sí la presencia de una turbación o de una afección en general, sino que la forma misma debe permanecer inmutable, y es la materia de esa forma la que debe verse envuelta en la afección cuando se vea envuelta en ella al suscitarla la forma con su presencia. Pues no es precisamente la facultad vegetativa la que vegeta cuando hace vegetar ni la que crece cuando hace crecer, y, en general, no es ella la que, cuando mueve, se mueve con aquel movimiento con que mueve, sino que o no se mueve en absoluto o se trata de un tipo distinto de movimiento, o sea, de actividad. Así pues, la naturaleza misma de la forma debe ser actividad y debe ser operativa por su presencia como una armonía que pulsara las cuerdas por sí misma (oĩov $\varepsilon i$

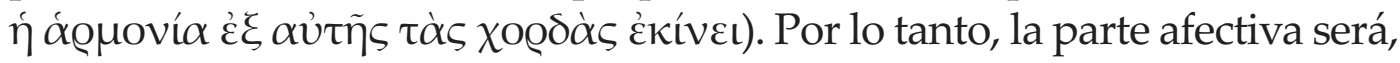


sí causa de afección, sea porque la afección proviene de ella bajo el impulso de la imaginación sensitiva, sea sin el impulso de la imaginación: esto habrá que estudiarlo, a ver si es porque la opinión toma la iniciativa desde arriba; mas la parte afectiva misma permanece inmutable al modo de una

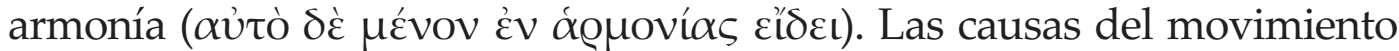
son análogas al músico, mientras que las partes golpeadas por la afección guardan analogía con las cuerdas. Pues aun allá, en la lira, la afectada no

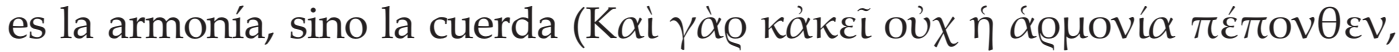
$\alpha \lambda \lambda^{\prime} \eta \dot{~ \chi o @ \delta \eta ்) . ~ N o ~ o b s t a n t e, ~ l a ~ c u e r d a ~ n o ~ s e ~ m o v e r i ́ a, ~ a u n q u e ~ e l ~ m u ́ s i c o ~ l o ~}$



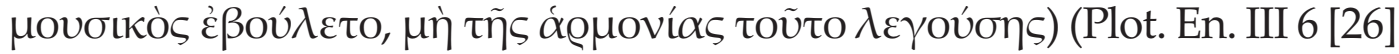
4, 30-52 Henry-Schwyzer, trad. Igal, ligeramente modificada).

El músico, que representa la causa eficiente del movimiento de las cuerdas, no es suficiente para producir un movimiento y otro, su acción es posible por la armonización que trata de introducir en las cuerdas. De este modo, el músico es como el alma, las cuerdas como el cuerpo que experimenta la afección, y la armonía inmanente que opera en las cuerdas como la opinión que mueve el cuerpo pero sin que se mueva a sí misma.

En este pasaje el argumento plotiniano introduce la noción de forma: "esa parte afectiva del alma no es un cuerpo, sino una forma (eîdos)”. Hasta este momento la oposición del alma a la afección se basaba en el análisis de la ousía, la realidad incorporal del alma (cf. En. III 6 [26] 1, 28; 2, 30 y 3, 32). A partir de ahora Plotino distingue la causa material, que identifica con la forma, de los efectos corpóreos en lo sensible; y, gracias a esta distinción, la forma inmaterial posibilitará salvaguardar la potencia afectiva de aquello que provoca.

Plotino sigue el De anima (II 4) de Aristóteles para explicar las tres facultades fundamentales de todo ser vivo: alimentación, crecimiento y reproducción. El deseo radica en la asociación del alma y del cuerpo, de ahí que insista en la relevancia no tanto de la naturaleza, sino de determinadas operaciones fisiológicas. Plotino compara el proceso natural de crecimiento con la producción de un sonido musical. Fleet (1995, p. 131-132) considera que MacKenna (1917-1930) y Armstrong 3 (1967, p. 229, v. 3) se equivocan

3 Plot. En. III 6 [26] 4, 41-44: "So, then, the actual nature of the form must be an activity, and produce by its presence, as if the melody proceeding form it plucked the strings" (trad. Armstrong). 
al interpretar la "armonía" en el sentido de "melodía" o "principio melódico". En el fondo el texto de las Enéadas remite a la explicación aristotélica del De anima, que define la armonía como "una proporción o combinación

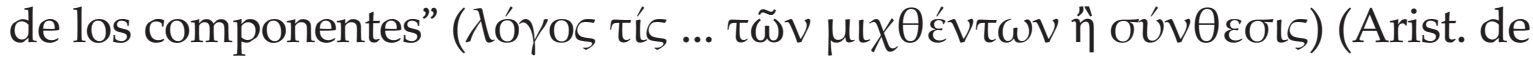
Anim. 407b p. 32-33). El propio Plotino otorga este sentido a la armonía cuando elabora la comparación en la que el músico y la armonización de-

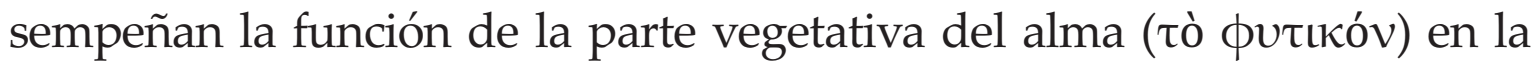
generación y el crecimiento, es decir, como causa eficiente.

En el tratado En. IV 7 [2] Sobre la inmortalidad del alma Plotino utiliza la comparación del alma con la armonía que surge de las cuerdas tensadas de un instrumento, lo que muestra su referencia a una pasaje del Fedón (85e-86d), al que aludiremos más adelante.

Y lo más importante realmente es que, anteriormente a esta alma, tendría que existir otra alma: la autora de esa armonía, que sería análoga al músico que en los instrumentos musicales imprime la armonía a las cuerdas

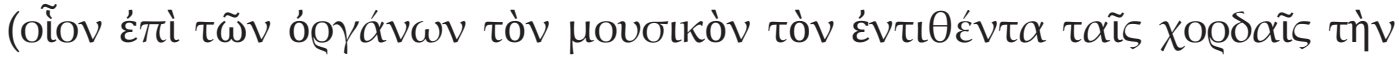
àguovíav) porque posee en su mente la proporción según la cual ha de

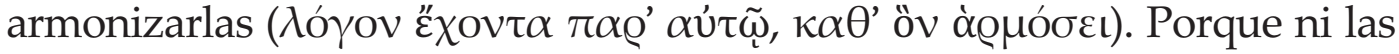
cuerdas en este caso ni los cuerpos en el nuestro son capaces de suyo de armonizarse a sí mismos. (En. IV 7 [2] 8, 17-23, trad. de Igal).

Este tratado En. IV 7, cronológicamente el segundo redactado por Plotino (Porph. Plot. 4, 24), en su composición formal es el más "escolar" de los tratados, $\mathrm{y}$, en lo referente a su temática, constituye una defensa de la concepción platónica del alma frente a otras escuelas. La primera parte de este tratado (caps. 2-8) es refutativa (IGAL, 1985, p. 485): el alma no es ni un conglomerado de átomos, contra los epicúreos, ni un pneûma corporal, contra los estoicos, ni tampoco una armonía, contra los pitagóricos, ni una actualidad inseparable, contra los peripatéticos. En el cap. 8 Plotino establece una correspondencia entre el alma y la armonía, pero la rechaza como argumento válido para probar la inmortalidad del alma. Sin embargo, aunque traza la comparación de los cuerpos con las cuerdas, aún no ha elaborado la teoría de la armonía trascendente en tanto forma, "que pulsara las cuerdas por sí misma" (En. III 6 [26] 4, 43), o "armonía separada" como la denomina Porfirio (Sent. 18, li. 9), diferente de la armonía 
que el músico introduce en las cuerdas, que la posee en sí mismo en tanto relación numérica (lógos) según la cual establece el acorde.

En el tratado En. IV 4 [28] Problemas acerca del alma (II), Plotino nos presenta un análisis sistemático de la unidad del universo y de la función de la simpatía ${ }^{4}$. La referencia a la sympátheia la realiza en conexión con el conocimiento de las plegarias y la magia, explicadas por la armonía de los astros. Las artes adivinatorias, la magia y las plegarias son fenómenos que Plotino no niega, pero que sitúa en relación con elementos transcendentes. Se trata de aspectos derivados de la interrelación material de las diversas partes de este universo.

Pero el sol u otro astro no se enteran; así que el influjo correspondiente a la plegaria se debe a que una parte entró en simpatía con otra, como ocurre en una misma cuerda cuando está tensada: al vibrar por la parte de abajo, vibra también arriba, y a menudo la vibración de una cuerda como que se deja sentir en otra por sintonización y porque está ar-

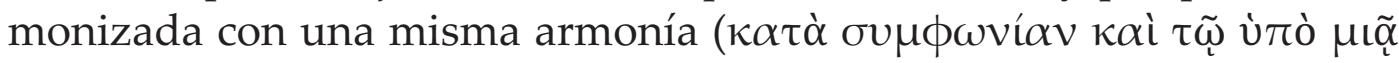

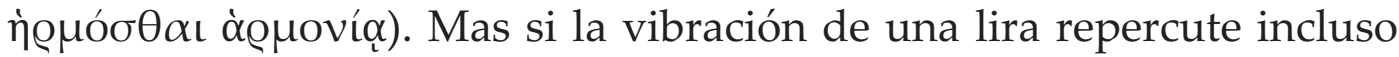

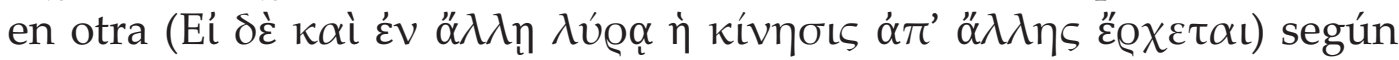

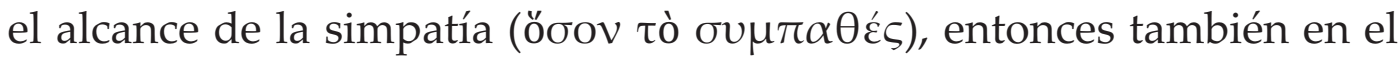


contrarios; además la armonía proviene tanto de componentes que son todos semejantes y afines como de los que son contrarios. (En. IV, 4 [28] 41, 1-9. Cf. En. IV, 4 [28] 26, 1-15).

En este pasaje, además de la referencia a la simpatía universal, Plotino relata un experimento musical que hallaremos expuesto posteriormente en el tratado Ad Gaurum escrito por su discípulo. Encontramos también dos liras, la tensión de una misma cuerda, las dos cuerdas consonantes que sintonizan y están armonizadas según la misma armonía, la vibración de una de ellas que repercute en la otra.

El universo sensible plotiniano se compone de una multitud de seres, no obstante, se mantiene como "uno", pues los seres que lo integran están en armonía con el todo y con ellos mismos. El todo es un organismo y forma "un mundo ordenado" (kósmos). Para expresar esta

4 Véase, especialmente, En. IV, 4 [28] 8, 52-61; 23, 9-29; 26, 1-15; 32, 13-22; 34, 9-13; 34, 26-33; 35, 8-16; 40, 1-4; y 41, 1-6. 
simpatía universal, o armonía universal, Plotino emplea la imagen de la danza, donde cada movimiento contribuye a la belleza del conjunto (En. IV 4 [28] 34, 26-33). La imagen del danzante se adapta a la vida del universo, hasta el punto que Plotino designa esta vida - donde no reina el azar, sino "una sola armonía y una sola ordenación" - como "la danza del universo" (En. IV 4 [28] 35, 8-16).

Si pudiéramos participar de la simpatía universal, de la simpatía total del universo consigo mismo, descubriríamos la interdependencia de las cosas con respecto al todo hasta en el más íntimo detalle. La imagen de la danza representa las diversas configuraciones de los astros a las que corresponden los cambios importantes de las cosas terrestres, por ejemplo, la producción de las diferentes especies animales y vegetales (cf. En. IV 4 [28] 33, 25-27).

Hay una coordinación universal de todos y cada uno de los acontecimientos. Un "acuerdo universal" ( $\tilde{u}^{\mu} \mu$ vot $\alpha \mu$ í $\alpha$ ), utilizando la expresión estoica que Plotino recoge en el tratado En. II 3 [52] Sobre si los astros influyen $(7,17-18)$, que no consiste en una intervención voluntaria de las realidades superiores en la vida de las de aquí. "El movimiento de los astros anuncia los acontecimientos futuros, pero no los produce" (En. II 3 [52] 1, 1-2). Las figuras celestes son solo signos, Plotino habla incluso de "letras" ( $\gamma \varrho \alpha ́ \mu \mu \alpha \tau \alpha)$ (cf. En. II 3 [52] 7, 4-14).

Cuando se conoce las afinidades y las correspondencias que existen naturalmente, es posible servirse de ese conocimiento ya sea para predecir, ya sea para producir ciertos efectos o hechos. Así que, para Plotino, la adivinación y las prácticas mágicas no guardan ningún carácter esotérico, solo es necesario saber para predecir y predecir para poder. De este modo, las prácticas mágicas se inscriben en el sistema plotiniano que expone en las Enéadas: la astrología es solo la ciencia de la armonía musical trasladada a la medida del universo, y las configuraciones de los astros, aunque no puedan por sí mismas producir los acontecimientos, forman parte de la organización del universo, ya que la simpatía que los coordina deja tras de sí signos que los anuncian. Por ello, si todo está entrelazado, si todas las cosas concuerdan unas con otras, es debido a que las prácticas de adivinación se explican por la simpatía y la correspondencia de los semejantes entre sí. En este 
punto la teoría plotiniana se halla próxima de la estoica. Pues, para los estoicos, la simpatía preside la estructura del mundo, el desarrollo de los acontecimientos y la sabiduría.

El dios estoico, confundido con el mundo y con todas las formas de lo real, es principio de cohesión y de simpatía de las cosas que une (cf. D.L. VII, 147). Así pues, la providencia estoica expresa la simpatía universal que une a todos los seres entre ellos y el desarrollo de los acontecimientos que traduce la vida del mundo. Sin embargo, es imposible otorgar cualquier clase de transcendencia a la providencia estoica, ya que es inmanente al mundo y expresión de la simpatía universal, el signo de la armonía de las partes con el todo. Así pues, la prónoia expresa la solidaridad íntima según un encadenamiento regulado de modo armónico en que las causas relacionan los acontecimientos entre ellos. Para los estoicos, dios es la "razón seminal del cosmos" y en él se contienen "todas las razones seminales según las cuales se origina cada cosa en conformidad con la fatalidad” (SVF II, 1027) 5 .

Para Plotino, la causa de la armonía universal ha de buscarse en las realidades superiores, "las cosas de abajo dependen de las de arriba - las de este universo, de las que son más divinas - y porque aun este universo participa de aquellas. Por consiguiente, las cosas de este universo no se originan por razones seminales, sino por razones inclusivas de contenidos anteriores aun a los que corresponden a las razones seminales" (En. IV 4 [28] 39, 3-7). Al lógos universal, anterior a su manifestación exterior, es a quien pertenece la organización que da cuenta de los hechos contingentes y que supone una especie de cálculo de los posibles, como el que


zación de un ejército obtuviera un resultado concreto (cf. En. III 3 [48] 2, 6-10). Ahora bien, no debemos tomar esta comparación al pie de la letra, e imaginar la providencia plotiniana calculando las suertes de cada parte para constituir el mejor de los mundos posibles, lo que la reduciría al nivel del artesano. La armonía de las partes no es querida expresamente y no proviene de una disposición de los elementos preexistentes: la causa de la multiplicad es la unidad que la precede, y es la unidad la que

5 Sobre la providencia en el estoicismo y el platonismo, véase Dörrie (1977, p. 82-85). 
explica el orden que ordena la multiplicidad. La armonía es una consecuencia sensible de la unidad inteligible que contempla la parte superior del Alma. Así, en la medida en que la forma inteligible, en lugar de permanecer encerrada en sí misma, se exterioriza, sus manifestaciones están necesariamente coordinadas. Por lo que todos los efectos de los astros están entretejidos en unidad y constituyen una armonía maravillosa.

Por tanto, la armonía representa la multiplicidad-una, donde la unidad es primera, porque proviene del modelo inteligible, y la multiplicidad segunda, no solo porque proviene de la razón espermática, sino porque se realiza en una sustancia sensible que tiende a la dispersión.

Plotino asimila la providencia a la parte inferior del Alma o phýsis, que, en los tratados Sobre la providencia [47 y 48] corresponde al demiurgo del Timeo, y califica de "principio director del universo" ( $\tau$ ò

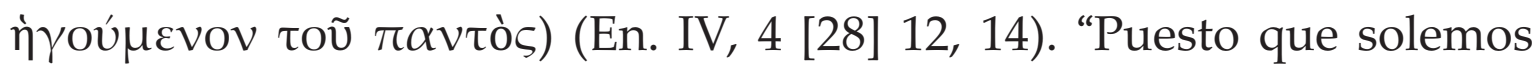
hablar del principio ordenador como doble: de un lado, como el demiurgo, y de otro, como el Alma del universo, así también, al hablar de Zeus, nos referimos a él unas veces como al demiurgo y otras como al

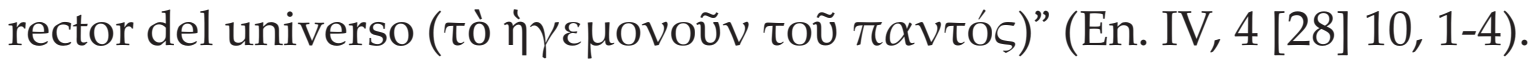
Así, el principio director "conoce el futuro", y este conocimiento representa el esquema dinámico de la creación del Alma-productora. No se trata, por tanto, de una previsión hipotética o parcial, sino, al contrario, de una visión global que opera en la producción del mundo sensible (cf. En. IV, 4 [28] 12, 22-24).

La armonía se debe tanto a la causalidad transcendente de la procesión, como a la causalidad inmanente de la participación, por la que el todo, en lugar de dividirse en las partes, permanece entero en cada una de ellas. Y esta participación depende no solo del Alma que contempla lo inteligible, o del Alma cósmica y providencial, sino más precisamente de las almas particulares inmanentes a la producción. Como hay un acuerdo de las almas con el orden del universo, no actúan de modo aislado, sino que modulan su descenso de acuerdo con el movimiento circular del mundo. El descenso de las almas a los cuerpos no es arbitrario; la noción de elección, para las almas individuales, depende en último término del destino. Por tanto, en Plotino la providencia universal es a la vez estoica, pues es inmanente, ya que es Zeus, vida, alma 
y orden del universo, y a la vez transcendente, ya que es el demiurgo quien construye un mundo ordenado.

\section{Porfirio: la armonía separada y la no separada}

En este contexto Porfirio acude en la Sentencia 18 a la comparación con la armonía, tomada del tratado plotiniano III 6 [26] 4: Sobre la impasibilidad de las cosas incorpóreas, para explicar de qué modo el alma, cuando está vinculada a un cuerpo y se produce una sensación, permanece impasible, mientras que el viviente se ve afectado.

La modificación de Porfirio radica en la distinción precisa de dos armonías - separada y no separada - según las cuales están afinadas las cuerdas consonantes. Asimismo, el filósofo de Tiro aplica a cada una de estas armonía una terminología propia y original. Precisamente, donde Plotino habla, para referirse de la realidad activa, de "otra" cuerda, "otra" lira, Porfirio opta por marcar claramente la diferencia entre la armonía "separada", que es autárquica, y la armonía "no separada", que rige la actividad del músico (SCHWYZER, 1974, p. 299; IGAL, 1979, p. 334).

Así pues, cada vez que el viviente se dedica a la sensación, su alma se

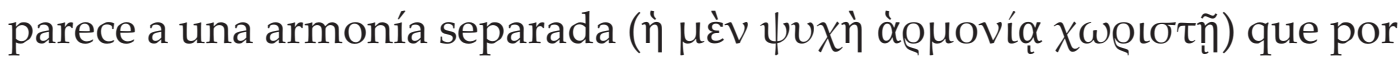
sí misma pone en movimiento las cuerdas afinadas por una una armonía no separada ( mientras que la causa de la puesta en movimiento, el viviente, debido a que es animado, corresponde al músico debido a que este es habitado por la armonía, mientras que los cuerpos golpeados, debido a que son afectados en la sensación, corresponden a las cuerdas afinadas; en efecto, en este ejemplo, no es la armonía la que ha padecido, la armonía separada, sino la cuerda. Y el músico da el movimiento según la

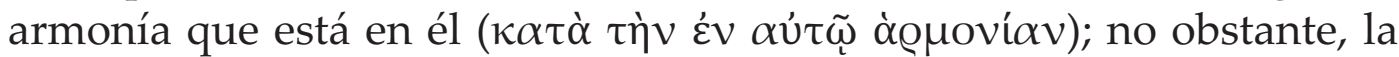
cuerda no se movería musicalmente, aunque el músico lo quisiera, si la

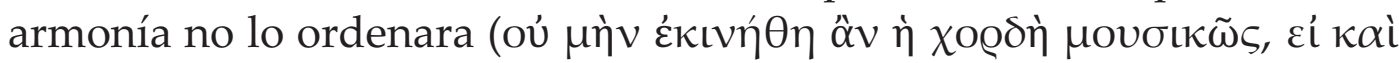

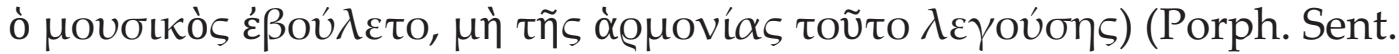
18, li. p. 8-18 BRISSON et al., 2005).

La comparación que establece Porfirio del funcionamiento de la sensación con la interpretación musical parte del pasaje plotiniano 
citado (En. III 6 [26] 4, 30-52). Ahora bien, aunque el filósofo de Tiro se mantiene fiel al sentido global del texto, introduce ciertas diferencias hermenéuticas que aparecen insertas en puntos específicos, como líneas asimétricas que se desvían de dos columnas paralelas. El alma es comparada con la armonía que por sí misma pulsa las cuerdas. Para Plotino esta causalidad que la armonía ejerce de modo espontáneo se corresponde con la del alma como forma, que "debe ser operativa por su presencia". Por su parte, Porfirio distingue la armonía "separada", cuya causalidad corresponde a la que desciende del mundo inteligible, de la armonía "no separada", inmanente al músico que se refiere a ella para afinar la lira. Esta armonía "separada", por la cual vibran las cuerdas dispuestas antes según una armonía "no separada" inmanente al alma del músico, alude al siguiente experimento acústico, inscrito en la tradición musical pitagórica (BURKERT, 1962, p. 354): el funcionamiento de una lira afinada con precisión activa la vibración de las cuerdas de otra lira separada sin que ningún músico la toque.

El propio Porfirio muestra su interés por este tipo de experimentos, en conexión con la interpretación de un pasaje del Timeo (35b$36 b)^{6}$ sobre la división del alma del mundo en función de intervalos armónicos ${ }^{7}$. Además de este pasaje, en el aparato crítico de las fuentes Lamberz señala un extracto del Fedón (85e-86d), donde Simmias enuncia la teoría de que el alma puede compararse con la armonía, algo divino, mientras que la lira bien afinada con sus cuerdas representaría el cuerpo mortal. Sin embargo, muy probablemente este discurso del Fedón no influye en Plotino ni tampoco en su discípulo Porfirio, puesto que el propio Simmias admite que de esta comparación derivaría la supresión de la inmortalidad del alma.

6 Macrobio comenta este pasaje del Timeo en términos de armonía musical (Macr. Comm. II 1, 5-7 y 14-25). Probablemente, estos pasajes del Comentario al Sueño de Escipión tengan como referencia el Comentario al Timeo de Porfirio (fr. 65 y 66 , p. 48, 15-49, 8 y 49, 9-52, 10 Sodano).

7 En Platón $\delta$ I áotn $\mu a$ puede tomar el sentido muy general de distancia, de diferencia entre dos magnitudes mensurables. Puede designar también la distancia entre dos sonidos, es decir, el intervalo musical (PI. R. 531a), expresado matemáticamente (PI. Phlb. 17c). Sobre los intervalos armónicos en Ti. 35b-36, pueden consultarse Grube (1932), Sonderegger (1997), Ferrari (1999), Lisi (2001), Del Forno (2005). Para los pormenores de la estructura matemática del alma del mundo, véase el Anexo 2 de Brisson en Zamora (2010, p. 426-429). 
El Comentario a las Harmónicas de Ptolomeo (DÜRRING, 1932 y 1934) presenta cierto interés para la historia de la música, ya sea por las informaciones que proporciona, o porque pertenece a una época de transición. La obra de Ptolomeo ${ }^{8}$, concebida desde el punto de vista de la teoría matemática de los acordes, interesa a Porfirio por su eclecticismo. En medio del caos de los sistemas y de los métodos adivinatorios introduce un orden basado en principios racionales. Porfirio expone sus posiciones sobre la estructura matemática del alma del mundo. En su exégesis se detiene en los primeros que se ocuparon del estudio de la armonía en la música, partiendo de los pitagóricos, especialmente de Eudoxo, de Platón, de los aristotélicos y de todos aquellos que establecieron doctrinas que permitieran "salvar los fenómenos". En este Comentario a las Harmónicas el filósofo de Tiro alude también, como en el texto de la Sent. 18 citado, a la distinción entre "armonía"

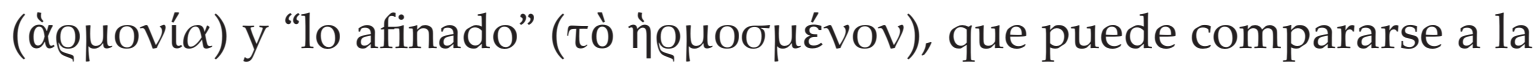
establecida entre el número y lo numerado (GERSH, 1992, p. 155).

Paralelamente, en el tratado Ad Gaurum quomodo animetur fetus (KALBFLEISCH, 1895; FESTUGIÈRE, 1953), Porfirio aborda la cuestión de la animación del embrión, es decir, descubrir en qué momento el alma racional entra en el cuerpo en formación. La formación del embrión se debe a la parte irracional del alma cósmica, y solo, en un segundo momento, cuando ya se han establecido las condiciones aptas para la recepción, el alma racional se une a él. Porfirio cita en este tratado el experimento de las dos liras:

Del mismo modo que dos cuerdas que estuvieran afinadas de la misma

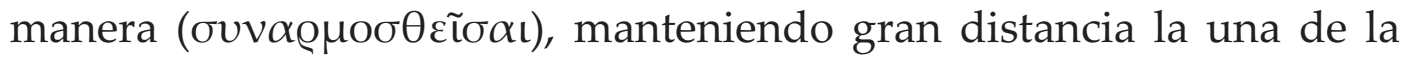
otra, si se hubieran puesto sobre ellas y sus contiguas unos fetos - suponiendo que las cuerdas contiguas no sean consonantes (óoú $\mu \phi \omega v o \iota)-y$ que una de las dos cuerdas consonantes fuera pulsada, las dos comienzan a vibrar y la sacudida hace caer los fetos, mientras que las cuerdas

8 Ptolomeo, buen conocedor de la tradición anterior, recopila material de procedencia diversa, lo que le permite construir sobre sólidos pilares un sistema teórico de tratadística musical griega, de manera similar al que elabora sobre teoría astronómica. En Harmónicas I 16 y III 16, Ptolomeo nos presenta una serie de afinaciones de instrumentos cordados, supuestamente empleados en su época. Aunque se trate de términos cuyo origen no está claro, reflejan claramente nombres conocidos dentro de la esfera de la música en la Grecia antigua. 
próximas están en reposo y se mantienen sin padecer ( $\alpha \dot{\pi} \alpha \theta \tilde{\omega} v)$ debido a su ausencia de consonancia [...], del mismo modo el cuerpo vivo, afinado como un instrumento en la aptitud del alma, obtiene inmediatamente la simpatía del alma que va a utilizarlo. (Porph. Gaur. XI 4, p. 49, 22-29 Kalbfleish).

En el tratado De musica9 Arístides Quintiliano relata el mismo dispositivo que Porfirio expone en el Ad Gaurum. Se trata de dos cuerdas pertenecientes a dos instrumentos distintos, pero afinadas de tal modo que producen el mismo sonido. En este caso, también la vibración de una activa la de la otra y precipita los fetos.

\section{Jámblico: el alma es una armonía matemática}

Conservamos largos extractos del Sobre el alma de Jámblico gracias a la Antología de Estobeo. En su Comentario al Sobre el alma atribuido en un primer momento erróneamente a Simplicio - y en su Metaphrasis in Theophrastum, Prisciano Lido (BYWATER, 1886) reconoce que toma de esta obra gran parte de las teorías expuestas con un carácter fundamentalmente doxográfico. Los fragmentos que conservamos, editados recientemente por Finamore y Dillon (2002), dan muestra del distanciamiento de Jámblico respecto a las posturas sobre el alma que defendían sus predecesores neoplatónicos, Plotino, Amelio y Porfirio.

A continuación, consideremos que es una armonía, no la inherente a los

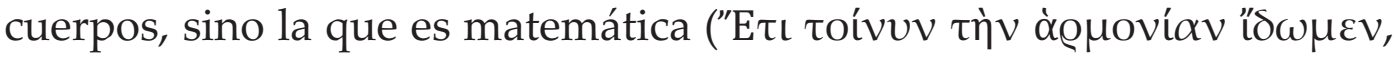


pues, la que hace simétricas y agradables las cosas divergentes en un modo u otro, la que Moderato relaciona con el alma. Timeo, por otra parte, refiere la armonía al alma en tanto es un medio y una conjunción en seres y vidas y la generación de todas las cosas (


Plotino, Porfirio y Amelio han enseñado que es la armonía en tanto

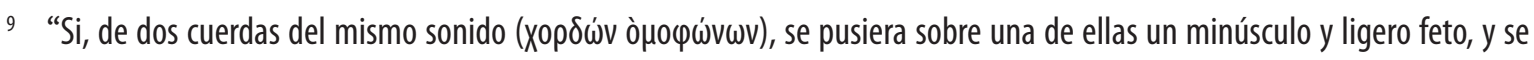
hiciera vibrar la otra tensada a distancia, veremos que de la manera más clara la que lleva el feto se pone al mismo tiempo en movimiento" (Aristid.Quint. II 18, p. 90, 2-5 Winnington-Ingram). 
reside en los principios racionales esencialmente preexistentes ( $\tau \dot{\eta} v \delta^{\prime}$

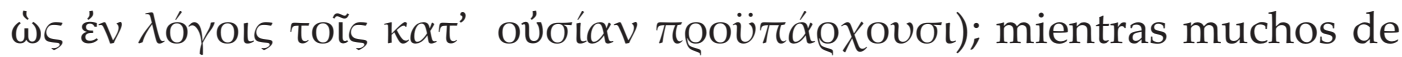
los platónicos y pitagóricos juzgan que es la armonía que está entreteji-



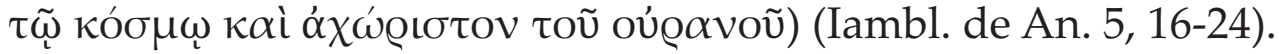

Para Moderato el alma es numérica en su esencia, en tanto que abarca todos los "principios racionales" (lógoi) ${ }^{10}$. Podemos interpretar esta concepción como una exposición de la doctrina pitagórica, pero empleando una terminología propia de la antigua Academia, en la que confluyen asimismo elementos estoicos. Los lógoi constituyen fórmulas matemáticas que el alma abarca en su totalidad (FINAMOREDILLON, 2002, p. 83-84).

La interpretación de Timeo a la que alude hace referencia al tratado Del alma del mundo y de la naturaleza de "Timeo de Lócride". Sin embargo, como Festugière (1953, p. 182-183, n. 8) sugiere, no hay nada en esta obra que se corresponda con la afirmación de Jámblico: “Timeo, por otra parte, refiere la armonía al alma en tanto que es un medio y una conjunción en seres y vidas y la generación de todas las cosas". No obstante, parece mantenerse fiel a la propuesta de Platón en Timeo (31b-32c, y 35a-36d), y alude a la alteración de esa armonía en tanto que es un medio y una conjunción causada por el trauma del nacimiento.

Asimismo, Jámblico expone la doctrina de Plotino, Porfirio y Amelio. Si bien, de este último no conservamos los textos. De Plotino se refiere al pasaje citado de En. IV 7 [2] $8^{4}$ 17-23, donde rechaza la doctrina del alma identificada solamente con una armonía. Sin embargo, aquí se ocupa del concepto de alma en tanto armonía preexistente, o en tanto transmisora de los lógoi portadores de armonía del mundo inteligible al cosmos físico como un todo y al cuerpo individual. Por su parte, Porfirio, como hemos visto, se refiere a una "armonía separada" en la Sentencia 18. Ahora bien, el aspecto relevante que aporta Jámblico a la exposición doxográfica de sus antecesores radica en la introducción de los números del alma, que son los que confieren armonía al

10 Sobre Moderato, puede verse Zamora (2012). 
mundo físico "de acuerdo con los principios racionales preexistentes en su esencia".

Más problemático resulta determinar la identidad de los platónicos y pitagóricos que consideran "que la armonía está entretejida con el cosmos y es inseparable del cielo". Probablemente se trate de platónicos medios de tendencia pitagórica, como Nicómaco de Gerasa, Numenio y el ya citado Moderato, pero también de no-pitagóricos como Ático, y algunos miembros de la antigua Academia. Del mismo modo, Jámblico critica a los comentadores anónimos que interpretan los números del alma refiriéndose a las distancias relativas entre cada una de las sietes esferas planetarias. En su trasfondo, se trata de la misma crítica que Porfirio ${ }^{11}$ dirige contra los platónicos anónimos que cayeron en el mismo error.

\section{Referencias}

ARMSTRONG, A. H. Plotinus. Ennead. Cambridge, MA: Harvard University Press, 1967. v. 3.

ARNIM, H. von. Stoicorum veterum fragmenta. Stuttgart: Teubner, 19031905. $4 \mathrm{v}$.

BRISSON, L. et al. Porphyre. Sentences. Paris: Vrin, 2005. 2 v.

BURKERT, W. Weisheit und Wissenschaft. Studien zu Pythagoras, Philolaos und Platon. Nürnberg: Carl, 1962.

BYWATER, I. Priscianus. Metaphrasis in Theophrastum. Berlin: Reimer, 1886. Commentaria in Aristotelem Graeca.

DEL FORNO, D. La struttura numerica dell'anima del mondo (Timeo, 35b4-36b6). Elenchos, v. 26, p. 5-32, 2005.

11 Apud Macr. Comm. II 3, 15. 
DÖRRIE, H. Der Begriff Pronoia in Stoa und Platonismus. Zeitschrift für Philosophie und Theologie, 24, p. 60-87, 1977.

DÜRING, I. Porphyrios Kommentar zur Harmonielehre des Ptolemaios. Göteborg: Nachdruck der Ausgabe, 1932.

DÜRING, I. Ptolemaios und Porphyrios über die Musik. Göteborg: Nachdruck der Ausgabe, 1934.

FERR ARI, F. Platone, Tim. 35a1-6 in Plutarco, An. Procr. 1012b-c: citazione ed esegesi. Rheinisches Museum für Philologie, v. 142, p. 326-340, 1999.

FESTUGIÈRE, A. J. A Gauros. Sur la manière dont l'embryon reçoit l'âme. In: FESTUGIÈRE, A. J. La Révelation d'Hermès Trimégiste, III: les doctrines de l'âme. Paris: Gabalda, 1953. p. 265-302.

FINAMORE, J. F.; DILLON, J. M. Iamblichus. De anima. Leiden: Brill, 2002.

FLEET, B. Plotinus: Ennead III.6, On the Impassivity of the Bodiless. Oxford: Clarendon Press, 1995.

GERSH, S. Porphyry's Commentary on the Harmonics of Ptolomy and Neoplatonic Musical Theory. In: GERSH, S.; KANNENGIESSER C. (Ed.). Platonism in Late Antiquity. Indiana: University of Notre Dame Press, 1992. p. 154-155.

GRUBE, G. M. The composition of the world-soul in Timaeus 35A-B. Classical philology, v. 27, p. 80-82, 1932.

HENRY, P.; SCHWYZER, H. R. Plotini opera. Oxford: Clarendon Press, 19641982. v. 3.

IGA L, J. Aristóteles y la evolución de la antropología de Plotino. Pensamiento, v. 35, p. 315-345, 1979.

IGAL, J. Plotino, Enéadas III-IV. Madrid: Gredos, 1985. v. 3.

KALBFLEISCH, K. Ad Gaurum. Berlin: Abhandlungen der Preussischen Akadamie der Wissenschaft. 1895.

LAMBERZ, E. Sententiae ad intelligibilia ducentes. Leipzig: Teubner, 1975. LISI, F. L. La creación en el Timeo 35 a-b. Hypnos, v. 7, p. 11-24, 2001. 
MACKENNA, S. Plotinus. The Enneads. London: Medici Society, 19171930. Disponible en: <http://classics.mit.edu/Plotinus/enneads.html>. Acceso en: 9 sept. 2011.

MARCOVICH, M. Diogenis Laertii Vitae philosophorum. Stuttgart: Teubner, 1999-2002. v. 3.

SCHWYZER, H.-R. Plotinisches und Unplotinisches in den 'AФOPMAI des Porphyrios. In: AA. VV. (Ed.). Plotino e il neoplatonismo in Oriente e in Occidente, Atti del Convegno (Roma, 5-9 ottobre 1970). Roma: Accademia Nazionale dei Lincei, 1974. p. 221-252.

SOD ANO, A. R. Porphyrii in Platonis Timaeum commentariorum fragmenta. Napoli: Instituto della Stampa, 1964.

SONDEREGGER, E. Die bildung der seele in platons timaios 35a1-b3. Museum Helveticum, v. 54, p. 211-218, 1997.

WACHSMUTH, C.; HENSE, O. Ioannis Stobaei Anthologium. Berlin: Weidmann. 1884-1912. v. 5.

W IL LIS, J. Ambrosii Teodosio macrobii commentarii in Somnium Scipionis. Leipzig: Teubner, 1970.

WINNINGTON-INGRAM, R. P. Aristidis quintiliani de musica libri tres. Leipzig: Teubner, 1963.

ZAMORA, J. M. Platón. Timeo, con notas y apéndices de L. Brisson. Madrid: Abada, 2010.

ZAMORA, J. M. Neopitagorismo en Hispania: moderato de Gades. Revista de Hispanismo Filosófico, v. 17, 2012. (en prensa).

Recibido: 03/02/2012

Received: 02/03/2012

Aprobado: 20/04/2012

Approved: 04/20/2012 